\title{
Disturbances of pulmonary function in patients with fat embolism ${ }^{1}$
}

\author{
C. PRYS-ROBERTS, R. GREENBAUM, J. F. NUNN, AND G. R. KELMAN \\ From the Department of Anaesthesia, University of Leeds
}

A number of theories have been advanced to explain the clinical syndrome of fat embolism, its diverse presentation, and in particular the unexplained rarity of the clinical syndrome as compared with the relatively common postmortem appearance of pulmonary fat embolism following trauma. Emphasis has recently been placed on the concurrent arterial hypoxaemia as a major factor contributing to the mortality of the condition (Sproule, Brady, and Gilbert, 1964; Greenbaum, Nunn, Prys-Roberts, Kelman, and Silk, 1965; Nunn, 1966; Collins, Gordon, Hudson, Irvin, Kelly, and Hardaway, 1968); Wertzberger and Peltier, 1968) but two conflicting theories of its causation have remained unresolved. The traditional view proposed by Gröndahl (1911) and supported by Armin and Grant (1951) and Sevitt (1962) maintains that the lethal effects are secondary to cerebral fat embolism rather than to embolization of fat in the lung capillaries. The opposite view holds that the arterial hypoxaemia is the predominant physiological disturbance, and that it results from deterioration in pulmonary function which arises directly from the embolization of fat in the lungs (Peltier, 1967). This view is also supported by Szabó (page 123). Previous reports have described desaturation of arterial blood in cases of fat embolism, but have provided little evidence of the causative mechanisms. This paper describes investigations of cardiopulmonary function made during 1965-66 in five patients in whom a clinical diagnosis of fat embolism was established. The patients were nursed in the Intensive Care Unit of the Leeds General Infirmary, and all observations made were incidental to the clinical management of the individual cases. A preliminary report has already been published (Greenbaum et al, 1965).

${ }^{1}$ Correspondence concerning this paper should be addressed to C. Prys-Roberts, Nuffield Dapartment of Anaesthetics, The Radcliffe Infirmary, Oxford.

\section{Case Reports}

\section{CASE 1}

D.W., a man aged 21 years, was involved in a road traffic accident and sustained a compound fracture of the left tibia and fibula, and a closed comminuted fracture of the left femur. He was fully conscious on admission, and there was no evidence of head injury. Internal fixation of the fractures was performed under general anaesthesia, from which he made a full recovery. Thirty-six hours after admission his body temperature rose to $39^{\circ} \mathrm{C}$ and he became drowsy although rousable. Sixty hours after admission he developed a petechial rash over the neck, chest, and axillae, and had a right fundal haemorrhage. His left arm showed increased muscle tone. He was treated with antibiotics, sedation, and oxygen therapy by a Venturi mask. A few hours later he complained of colicky abdominal pain, and became increasingly agitated, with respiratory distress and rapid, shallow breathing. A tracheostomy was performed and artificial ventilation by intermittent positive pressure ventilation started. The inspired oxygen concentration was raised to more than $60 \%$ in order to maintain adequate arterial oxygen tensions $\left(\mathrm{PaO}_{2}\right)$. Consciousness deteriorated progressively, and subsequently he became intensely cyanosed unless he was ventilated with $100 \%$ oxygen.

On the tenth day, bowel sounds were absent and there was abdominal wall rigidity, so a laparotomy was performed which revealed bilestained peritoneal fluid with much gas, a necrotic spleen with thrombosed vessels, and a large gastric perforation. A heavy growth of Clostridium welchii was cultured from the spleen, and he was treated with tetracycline and hydrocortisone. At this stage his pulmonary function was improving, 
but on the twelfth day he developed a left tension pneumothorax which was drained. A pericardial effusion was drained on the thirteenth day, but he died on the following day.

Cardiopulmonary function is shown in Table I.

\section{Necropsy findings}

Slight cerebral oedema, bilateral suppurative pneumonia and pulmonary collapse, pleural and pericardial effusions, ascites, and hepatic infarcts were found.

\section{CASE 2}

M.C., a man aged 18, sustained a closed fracture of the left femur and a compound fracture of the right tibia and fibula in a road traffic accident. Five days after admission he suddenly became incoordinated and drowsy, developed axillary petechiae, and a right fundal haemorrhage. His breathing was laboured at a rate of 40 per minute, and a chest radiograph showed the characteristic snowstorm opacities throughout both lung fields. He was given oxygen therapy by a Venturi mask with inspired $\mathrm{O}_{2}$ concentrations up to $63 \%$. Haemoglobin was found to be $6.9 \mathrm{~g} / 100 \mathrm{ml}$, and he was transfused with blood and low molecularweight dextran (Rheomacrodex). By the twelfth day he was clinically fully recovered. Cardiopulmonary function is detailed in Table II.
CASE 3

R.L., a woman aged 53, was involved in a roogd traffic accident and was unconscious on admission. She sustained a closed fracture of the right tibia and fibula, and a compound fracture of right femur. External reduction and fixation of fractures was performed under general anaesthesia. On the second day after admissiow, having regained consciousness, she then becane drowsy, and developed a petechial rash over anterior and posterior chest walls. She had mo respiratory distress, and her chest radiograph was clear. She made an uneventful recovery. Cardiopulmonary investigations are detailed in Table

\section{CASE 4}

F.W., a woman, aged 75 , sustained a closed fracture of the right femoral shaft and a compound fracture of the right tibia and fibula in a road traffic accident. Internal fixation of the femoral fracture and closed reduction of the lower leg fractures were performed under general anaesthesia. She did not fully regain consciołsness after this procedure, but remained drow and slowly responsive to painful stimuli. On the second day, a petechial rash developed over the upper chest, and in spite of hyperventilation sibe became cyanosed while breathing air. A tracheestomy was performed and she breathed humidifed

\begin{tabular}{|c|c|c|c|c|c|c|c|c|c|c|c|c|}
\hline $\begin{array}{l}\text { Time } \\
\text { (days) }\end{array}$ & Ventilation & $\begin{array}{l}\dot{V}_{E} \\
(l / \min )\end{array}$ & $\begin{array}{l}f \\
(\text { per } \\
\text { min) }\end{array}$ & $\begin{array}{l}\mathrm{Hb} \\
(\mathrm{g} \text { per } \\
100 \mathrm{ml})\end{array}$ & $\mathrm{FIO}_{2}$ & $\begin{array}{l}P A O_{2} \\
(m m H g)\end{array}$ & $\begin{array}{l}\mathrm{PaO}_{2} \\
(\mathrm{~mm} \mathrm{Hg})\end{array}$ & $\begin{array}{l}\mathrm{PaCO}_{2} \\
(\mathrm{~mm} \mathrm{Hg})\end{array}$ & $\begin{array}{l}\dot{V} \mathrm{O}_{2} \\
(\mathrm{ml} / \mathrm{min}) \\
S T P D\end{array}$ & $\begin{array}{l}V_{D} / V_{T} \\
(\%)\end{array}$ & $\underset{(\%)}{\phi_{s} / \phi_{t}}$ & $\begin{array}{l}\text { Cardia } \overrightarrow{8} \\
\text { Output } \\
(\text { l/min })^{-}\end{array}$ \\
\hline 2 & SV & 33.0 & 50 & $12 \cdot 0$ & 0.21 & 108 & 37 & 27 & 520 & 56.0 & 55.0 & - \\
\hline 3 & SV & - & - & 11.9 & 0.62 & 408 & 72 & 40 & - & - & - & - \\
\hline 4 & SV & - & - & $10 \cdot 8$ & 0.35 & 216 & 34 & 32 & - & - & - & - \\
\hline 5 & IPPV & $17 \cdot 0$ & 22 & 8.4 & 1.00 & 682 & 165 & 33 & 404 & $51 \cdot 0$ & $37 \cdot 0$ & - \\
\hline 6 & IPPV & 12.0 & 20 & $9 \cdot 7$ & 1.00 & 675 & 229 & 34 & 260 & 50.0 & 39.0 & $9 \cdot 10$ 윽 \\
\hline 8 & IPPV & 16.0 & 18 & 10.4 & 1.00 & 673 & 240 & 27 & 328 & 48.0 & 30.0 & $10.70 \Omega$ \\
\hline 10 & IPPV & $17 \cdot 0$ & 17 & $12 \cdot 0$ & 0.81 & 535 & 225 & 33 & - & 34.0 & 18.0 & - \\
\hline 11 & IPPV 2 & - & - & $14 \cdot 3$ & 0.76 & 512 & 85 & 28 & - & 一 & - & - \\
\hline 12 & IPPV & 16.8 & 17 & $12 \cdot 3$ & 0.75 & 498 & 152 & 35 & 391 & 33.0 & $21 \cdot 0$ & - \\
\hline
\end{tabular}

Table I Results of sequential investigations in case $1^{1}$

${ }^{1}$ Riley-Cournand analyses were performed with a physiological mouthpiece during spontaneous ventilation. ${ }^{2}$ Measurements before drainage of pneumothorax.

\begin{tabular}{|c|c|c|c|c|c|c|c|c|c|c|c|}
\hline $\begin{array}{l}\text { Time } \\
\text { (days) }\end{array}$ & $\begin{array}{l}\dot{V}_{E} \\
\text { (litres } \\
\text { per } \\
\text { minute) }\end{array}$ & $\begin{array}{l}f \\
\text { (per } \\
\text { minute) }\end{array}$ & $\begin{array}{l}\mathrm{Hb} \\
(\mathrm{g} / 100 \mathrm{ml})\end{array}$ & $\mathrm{FIO}_{2}$ & $\begin{array}{l}P A O_{2} \\
(m m \mathrm{Hg})\end{array}$ & $\begin{array}{l}\mathrm{PaO}_{2} \\
(\mathrm{~mm} \mathrm{Hg})\end{array}$ & $\begin{array}{l}\mathrm{PaCO}_{2} \\
(\mathrm{~mm} \mathrm{Hg})\end{array}$ & $\begin{array}{l}\dot{V} O_{2} \\
(m l / m i n) \\
S T P D\end{array}$ & $\begin{array}{l}V_{D} / V_{T} \\
(\%)\end{array}$ & $\underset{(\%)}{Q} s / \dot{Q} t$ & $\begin{array}{l}\text { Cardi } \\
\text { Outpu } \\
\text { (l/min }\end{array}$ \\
\hline 6 & $16 \cdot 2$ & 30 & 6.9 & 0.21 & 108 & 40 & 30 & 390 & 48.0 & 55.0 & - \\
\hline 7 & - & - & - & 0.63 & 420 & 110 & 28 & - & - & - & - \\
\hline 8 & - & - & - & 0.49 & 350 & 127 & 31 & - & - & - & - \\
\hline 9 & $17 \cdot 0$ & 24 & 10.9 & 0.21 & 104 & 65 & 33 & 498 & $37 \cdot 0$ & $21 \cdot 0$ & - \\
\hline 13 & $10 \cdot 2$ & 17 & 10.9 & 0.21 & 106 & 79 & 30 & 374 & 23.0 & 15.6 & 13.8 \\
\hline
\end{tabular}

Table II Results of Riley-Cournand analyses during spontaneous ventilation in case 2

The abbreviations set out below apply to Tables I-IV.

$\dot{\mathrm{V}}_{\mathrm{E}}=$ minute volume of ventilation; $\mathrm{f}=$ frequency of breathing; $\mathrm{FIO}_{2}=$ fractional concentration $\mathrm{O}_{2}$ inspired; $\mathrm{PAO} \mathrm{O}_{2}=$ alveolar ${ }_{0}$ oxygen tension; $\mathrm{PaO}_{2}=$ arterial $\mathrm{PO}_{2} ; \mathrm{PaCO}_{2}=$ arterial $\mathrm{PCO}_{2} ; \dot{\mathrm{VO}} \mathrm{O}_{2}=$ oxygen uptake; VD/VT $=$ dead-space to tidal volume ratio. $\mathbf{Q}_{\mathrm{s}} / \mathbf{Q}_{\mathrm{t}}=$ pulmonary venous admixture; $\mathbf{S V}=$ spontaneous ventilation; $\mathbf{I P P V}=$ intermittent positive pressure ventilation. 
oxygen-enriched air spontaneously, but with increasing respiratory distress. Intermittent positive pressure ventilation was instituted on the fourth day with $100 \%$ oxygen. She died on the fifth day.

\section{Necropsy findings}

Numerous petechial haemorrhages were found throughout the white and grey matter of the brain. The lungs were brawny and showed multiple small abscesses. Histology confirmed both pulmonary and cerebral embolization of fat.

Cardiopulmonary investigations are also detailed in Table III.

\section{CASE 5}

C.L., a man aged 28 , a heavily pigmented Negro weighing over $100 \mathrm{~kg}$, was crushed and trapped by a large falling concrete slab. His left arm was virtually severed from the body at the shoulder, and he sustained a fractured skull and fractured pelvis. Under general anaesthesia, a transglenoid amputation of the left arm was performed, the compound skull fracture was explored, and corneal lacerations were repaired. Five litres of blood were transfused together with 250 m-equiv of sodium bicarbonate. He recovered consciousness, and although drowsy, was cooperative and responded to questioning. He had a left hemiplegia, and there was paradoxical movement of the left side of the chest, but no evidence of chest injury. Cardiopulmonary investigations at this stage showed normal dead-space/tidal volume ratios and moderate impairment of oxygenation with characteristic features associated with injury. Subsequent studies demonstrated increased deadspace/tidal volume ratios (see Table IV and results) which induced suspicion of a fat embolism. Because of his deeply pigmented skin, it was impossible to ascertain the existence of petechiae, but there were conjunctival petechiae, and fat globules were seen on microscopy of the serum. He was breathing rapidly ( 38 per minute) and was maintaining a high minute volume by spontaneous ventilation. His inspired oxygen concentration was raised to and maintained at $30 \%$ by a Venturi mask. He made a progressive and uneventful recovery. Details of the cardiopulmonary investigations are shown in Table IV.

\section{Methods of Cardiopulmonary Investigation}

The investigations carried out on these patients followed the principles described by Nunn (1969) and were based on the classical methods of Riley, Cournand, and Donald (1951). These methods of analysis of the distribution of ventilation and perfusion allow a distinction to be made between disturbances of alveolar perfusion and those of alveolar ventilation. The former may occur following the pulmonary embolization of blood thrombi (Stein, Forkner, Robin, and Wessler, 1961), fat or air (Severinghaus and Stupfel, 1957), or a severe reduction in total pulmonary perfusion as a result of reduced cardiac output during haemorrhagic shock (Freeman and Nunn,

\begin{tabular}{|c|c|c|c|c|c|c|c|c|c|c|c|c|}
\hline $\begin{array}{l}\text { Case } \\
\text { No. }\end{array}$ & $\begin{array}{l}\text { Time } \\
\text { (days) }\end{array}$ & $\begin{array}{l}\dot{V}_{E} \\
\text { (litres } \\
\text { per } \\
\text { minute) }\end{array}$ & $\begin{array}{l}f \\
\text { (per } \\
\text { minute) }\end{array}$ & $\begin{array}{l}H b \\
(\mathrm{~g} / 100 \\
m l)\end{array}$ & $\mathrm{FIO}_{2}$ & $\begin{array}{l}P_{A O_{2}} \\
(m m ~ H g)\end{array}$ & $\begin{array}{l}\mathrm{PaO}_{2} \\
(\mathrm{~mm} \mathrm{Hg})\end{array}$ & $\begin{array}{l}\mathrm{PaCO}_{2} \\
(\mathrm{~mm} \mathrm{Hg})\end{array}$ & $\begin{array}{l}\dot{V} O_{2} \\
(m l / m i n) \\
S T P D\end{array}$ & $\begin{array}{l}V_{D} / V_{T} \\
(\%)\end{array}$ & $\begin{array}{l}\phi_{s} / \phi_{t} \\
(\%)\end{array}$ & $\begin{array}{l}\text { Cardiac } \\
\text { Output } \\
\text { (l/min) } \\
\text { (dye) }\end{array}$ \\
\hline 3 & 2 & $6 \cdot 0$ & 18 & $16 \cdot 6$ & 1.00 & 676 & 560 & 39 & - & $39 \cdot 6$ & $6 \cdot 7$ & - \\
\hline 4 & $\begin{array}{l}2 \\
2 \\
3 \\
4\end{array}$ & $\begin{array}{l}10.0 \\
- \\
8.7\end{array}$ & $\frac{22}{\frac{-}{26}}$ & $\begin{array}{l}11.0 \\
11.0 \\
-10.7\end{array}$ & $\begin{array}{l}0.21 \\
1.00 \\
0.48 \\
1.00\end{array}$ & $\begin{array}{l}118 \\
687 \\
306 \\
680\end{array}$ & $\begin{array}{l}36 \\
90 \\
53 \\
80\end{array}$ & $\begin{array}{l}24 \\
30 \\
25 \\
39\end{array}$ & $\begin{array}{l}228 \\
228 \\
- \\
-\end{array}$ & $\begin{array}{l}41 \cdot 0 \\
- \\
61 \cdot 0\end{array}$ & $\begin{array}{l}41 \cdot 3 \\
27 \cdot 7 \\
\overline{30 \cdot 4}\end{array}$ & $\frac{5.08}{-}$ \\
\hline
\end{tabular}

Table III Results of Riley-Cournand analyses in cases 3 and 4 during spontaneous ventilation

\begin{tabular}{|c|c|c|c|c|c|c|c|c|c|}
\hline $\begin{array}{l}\text { Time } \\
\text { (days) }\end{array}$ & $\begin{array}{l}\dot{V}_{E} \\
\text { (litres per } \\
\text { minute) }\end{array}$ & $\begin{array}{l}f \\
\text { (per } \\
\text { minute) }\end{array}$ & $\begin{array}{l}\mathrm{Hb} \\
(\mathrm{g} / 100 \mathrm{ml})\end{array}$ & $\mathrm{FIO}_{2}$ & $\begin{array}{l}\mathrm{PAO}_{2} \\
(\mathrm{~mm} \mathrm{Hg})\end{array}$ & $\begin{array}{l}\mathrm{PaO}_{2} \\
(\mathrm{~mm} \mathrm{Hg})\end{array}$ & $\begin{array}{l}\mathrm{PaCO}_{2} \\
(\mathrm{~mm} \mathrm{Hg})\end{array}$ & $\begin{array}{l}V_{D} / V_{T} \\
(\%)\end{array}$ & $\underset{(\%)}{\dot{Q} s / Q t}$ \\
\hline $\begin{array}{l}1 \\
2^{1} \\
3 \\
4 \\
7\end{array}$ & $\begin{array}{l}10.9 \\
13 \cdot 2 \\
12.5 \\
14 \cdot 2 \\
15.6\end{array}$ & $\begin{array}{l}26 \\
38 \\
37 \\
38 \\
37\end{array}$ & $\begin{array}{l}11.4 \\
11.2 \\
11.9 \\
10.4 \\
10.3\end{array}$ & $\begin{array}{l}1.00 \\
1.00 \\
1.00 \\
0.98 \\
0.95\end{array}$ & $\begin{array}{l}661 \\
661 \\
653 \\
662 \\
671\end{array}$ & $\begin{array}{l}425 \\
271 \\
348 \\
329 \\
320\end{array}$ & $\begin{array}{l}36 \\
42 \\
45 \\
39 \\
32\end{array}$ & $\begin{array}{l}41 \cdot 5 \\
54 \cdot 5 \\
57 \cdot 0 \\
49 \cdot 5 \\
37 \cdot 2\end{array}$ & $\begin{array}{l}12.0 \\
20.0 \\
16.1 \\
17.5 \\
18.0\end{array}$ \\
\hline
\end{tabular}

Table IV Details of Riley-Cournand analyses in case 5 during spontaneous ventilation through a physiological mouthpiece 


\section{Prys-Roberts, R. Greenbaum, J. F. Nunn, and G. R. Kelman}

1963). Disturbances of alveolar ventilation may be general or regional, the former being the result of alveolar hypoventilation, whereas regional disturbances may arise from lobar or segmental atelectasis, pneumothorax, or when a significant population of alveoli cannot take part in gas exchange because their lumina are filled or occluded by fluid (eg, pulmonary oedema), blood, fibrin, or fat or its degradation products.

During spontaneous ventilation, patients breathed either air or $100 \%$ oxygen through a non-return valve connected to a tracheostomy or to a physiological mouthpiece. Intermittent positive pressure ventilation was maintained either with air, oxygen-enriched air, or $100 \%$ oxygen delivered by a constant volume ventilator (Cape Engineering Co. Ltd, Warwick) using deliberately high tidal volumes $(800-1,100 \mathrm{ml})$ at a slow rate (8-10 per minute). Expired gas was collected in plastic Douglas bags over two-minute periods and the volume collected was measured with a dry gas meter. Concentrations of oxygen in the inspired and expired gas mixtures were analysed with a Servomex DCL 101 paramagnetic oxygen analyzer. Expired concentration of carbon dioxide was analysed with a Lloyd-Haldane apparatus. Samples of arterial and mixed venous blood were simultaneously collected from catheters placed respectively in the brachial artery, or floated from an arm vein into either right ventricle or pulmonary artery. These blood samples were immediately analysed at $37^{\circ} \mathrm{C}$ for $p \mathrm{H}$ by capillary microelectrode, and for $\mathrm{PCO}_{2}$ by the interpolation technique using Radiometer equipment (Kelman, Coleman, and Nunn, 1966). $\mathrm{PO}_{2}$ was measured with a Beckman macrocathode polarograph. Oxygen content was measured by the polarographic method described by Linden, Ledsome, and Norman (1965). In cases 1 and 2, cardiac output was estimated by the Fick method, whereas in case 4 it was measured by the indicator dilution technique using indocyanine green dye. Alveolar oxygen tension was derived from the formula proposed by Nunn (1963) or from a simplified form of the alveolar air equation when patients were breathing $100 \%$ oxygen: $\mathrm{PAO}_{2}=\mathrm{PIO}_{2}$ $\mathrm{PaCO}_{2}-\mathrm{PH}_{2} \mathrm{O}$. Estimates of the alveolararterial $\mathrm{PO}_{2}$ difference $\left(\mathrm{PAO}_{2}-\mathrm{PaO}_{2}\right)$, percentage pulmonary venous admixture $(\dot{Q} / \mathbf{Q} t)$, dead-space/tidal volume ratio $(\mathrm{VD} / \mathrm{VT})$, oxygen uptake $\left(\dot{\mathrm{VO}}_{2}\right)$, and arteriovenous oxygen content difference $\left(\mathrm{CaO}_{2}-\mathrm{C} \overline{\mathrm{O}_{2}}\right)$ were made using conventional formulae (Nunn, 1969). ${ }^{1}$ The detailed methodology used in this study has been described

${ }^{1}$ Normal values for healthy young subjects.

VD/VT: $\quad 25-35 \%$. The value increases with age, and particularly in lung diseases which cause ventilation/perfusion disturbances. Tracheostomy reduces VD/VT to between 15 and $30 \%$ in the same group of subjects.

Q́s/Qt: $\quad 2-8 \%$ when breathing air; $2-6 \%$ when breathing $100 \% \mathrm{O}_{2}$. Qs/Qt also increases with age.

$\mathrm{CaO}_{2}-\mathrm{CvO}_{2}: 3 \cdot 5-5.0 \mathrm{ml} / 100 \mathrm{ml}$

$\mathrm{PAO}_{2}-\mathrm{PaO}_{2}$ : $5-20 \mathrm{~mm} \mathrm{Hg}$ breathing air; $20-80 \mathrm{~mm} \mathrm{Hg}$ when breathing $100 \% \mathrm{O}_{2}$. elsewhere (Kelman and Prys-Roberts, 1967) Riley analyses were usually performed daily.

\section{Results}

The results of the studies in individual patients are detailed in Tables I-IV. In all the patients, $\vec{a}$ raised $V_{D} / V_{T}$ was found either at the initial study or on the second occasion (case 5), but tended to. fall towards normal values $(25-35 \%)$ within the first three to six days. Venous admixture remained high for much longer periods, even in those patients who recovered.

\section{CASE 1}

During spontaneous ventilation in the earl stages, this patient had a high oxygen uptake $(520 \mathrm{ml} / \mathrm{min}$, approximately $200 \%$ of the pre응 dicted basal oxygen uptake for a man of his age and size), a very high VD/VT $(56 \%)$ associate with marked hyperventilation (VE: 33 litres/min $\mathrm{f}=50$ per minute), and was markedly hypox aemic when breathing air $\left(\mathrm{PaO}_{2}: 37 \mathrm{~mm} \mathrm{Hg}\right.$ $\mathrm{SaO}_{2}: 68 \%$ ) as a result of a severe degree of pulmonary venous admixture (Q́s/Q́t: $55 \%$ ) Subsequent measurements under intermitteno positive pressure ventilation with $100 \% \mathrm{O}_{\frac{2}{2}}$ showed that between the fifth and the tenth day his $\mathrm{VD} / \mathrm{VT}$ fell from 51 to $34 \%$, implying a improvement in the overall and regional pero fusion of the lungs. Although the pulmonar venous admixture also improved at the same times the values did not approach normality and ind售 cated a marked degree of ventilatory disturbance even at a time when $V D / V T$ was within the normal range. Oxygen uptake also decreased but still remained high when compared with norma values for patients on artificial ventilations Despite the improvements he still needed $76^{\circ}$ inspired $\mathrm{O}_{2}$ to maintain a 'normal' $\mathrm{PaO}_{2}$ of $85 \mathrm{~mm} \mathrm{Hg}$ on the eleventh day. Estimations of airway mechanics on the tenth day yielde evidence of marked reduction of pulmonary coms pliance $\left(29 \mathrm{ml} / \mathrm{cm} \mathrm{H}_{2} \mathrm{O}\right)$ but normal values for airway resistance $(0.025 \mathrm{~cm} \mathrm{H} / \mathrm{O} / \mathrm{ml}$ at a flow $865 \mathrm{ml} \mathrm{O}_{2} / \mathrm{sec}$ ). On the sixth and eighth day心 cardiac output was raised to approximately 2000 of the predicted resting levels, but was in propore tion to the increased oxygen uptake, yielding suber normal values of $\mathrm{CaO}_{2}-\mathrm{CvO}_{2}(2 \cdot 9-3 \cdot 1 \mathrm{ml} / 100 \mathrm{ml})$ ?

CASE 2

This patient initially showed essentially the same pattern as case 1 of raised oxygen uptak (390-498 ml/min STPD), raised VD/VT (46-48\% and markedly raised venous admixture $(55 \%)$. Bg the time that he had clinically recovered, his $\mathrm{VD} / \mathrm{VT}$ had returned to normal, although the venous admixture was still abnormally high 
$(15 \%)$. Despite spontaneous hyperventilation $\left(\mathrm{PaCO}_{2}: 30 \mathrm{~mm} \mathrm{Hg}, \mathrm{VE}: 16\right.$ litres/minute), this patient was also severely hypoxaemic when breathing air $\left(\mathrm{PaO}_{2}: 40 \mathrm{~mm} \mathrm{Hg} ; \mathrm{SaO}_{2}: 72 \%\right)$.

\section{CASE 3}

This patient showed remarkably little evidence of pulmonary dysfunction when breathing $100 \%$ oxygen, and her VD/VT and Q́s/Qt values were within normal limits for a woman of her age.

\section{CASE 4}

This patient was severely hypoxaemic when breathing air $\left(\mathrm{PaO}_{2}: 36.5 \mathrm{~mm} \mathrm{Hg} ; \mathrm{SaO}_{2}: 67 \%\right)$ and had a grossly elevated VD/VT $(60 \%)$ and Qs/Qt (30-40\%) up to the time of death. Her cardiac output and oxygen uptake values were within normal limits.

\section{CASE 5}

The findings in this patient were unique, in that a set of measurements made on the first day of admission showed essentially normal gas exchange, whereas the diagnosis of fat embolism was first suspected as a result of the marked elevation in VD/VT found on the second day, together with increased Q $\mathbf{s} / \mathbf{Q} t$, and subsequently confirmed by the stigmata of systemic fat embolism. Although the $\mathrm{VD} / \mathrm{VT}$ in this patient returned rapidly to normal, the venous admixture remained raised beyond the sixth day. Although this patient was not allowed to become hypoxaemic, it is difficult to interpret the central nervous disturbances in view of his preexisting head injury.

\section{Discussion}

It has been suggested that pulmonary fat embolism alone is insufficient to cause disturbances of gas exchange in previously healthy subjects (Szabó, Jankovics, and Farkas, 1969) or to account for the clinical syndrome and the mortality arising from it (Sevitt, 1962). With the exception of case 3, the most striking feature of the measurements of pulmonary gas exchange described in this paper was the severe disturbance of ventilation/perfusion relationships, in each case causing marked desaturation of arterial blood to a degree similar to that described by previous authors (Sproule et al, 1964; Collins et al, 1968; Wertzberger and Peltier, 1968; Szabó et al, 1969).

The changes in VD/VT found in the early stages of the syndrome, and which decreased steadily towards normal values over a period of days, are compatible with a significant obstruction to pulmonary perfusion, either on a regional or a diffuse basis. Indeed it would have been surprising if such changes had not been found, since they could have been predicted from a knowledge of the proportion of pulmonary capillaries occluded by fat at any one time. Similar changes in $\mathrm{VD} / \mathrm{VT}$ have been found in other pulmonary embolic conditions, the effect being attributed to an increase in the alveolar component of the total dead space. The migration of peripheral thrombi into the pulmonary circulation has been shown to cause increased alveolar dead space both in dogs (Stein et al, 1961) and in man (Prys-Roberts, unpublished observations); air embolism causes a similar effect (Severinghaus and Stupfel, 1957). Impaired perfusion of the pulmonary capillaries due to reduced cardiac output may occur either during haemorrhagic shock (Gerst, Rattenborg, and Holaday, 1959; Freeman and Nunn, 1963) and during deliberate hypotension (Eckenhoff, Enderby, Larson, Edridge, and Judevine, 1963). It is of course important to exclude these other causes before attributing the measured changes in $\mathrm{VD} / \mathrm{VT}$ to the embolization of fat, but in none of our patients was there any evidence of such changes; indeed the cardiac output estimations yielded values which were higher than normal. Similar findings were described by Sproule et al (1964). Increased alveolar dead space implies a wastage of ventilatory volume and a gross inefficiency of carbon dioxide elimination (Enghoff, 1938); thus, in order to maintain normal arterial carbon dioxide tensions, the patient has to increase his minute volume, particularly when carbon dioxide production is increased in parallel with the raised oxygen consumption. Other mechanisms clearly play some part in the generation of the tachypnoea, which is a characteristic feature of pulmonary embolism with either fat, air, or thrombi (Binger, Brown, and Branch, 1924), and the alveolar hyperventilation which maintains subnormal levels of arterial $\mathbf{P C O}_{2}$. Only in case 5 was there evidence of raised arterial $\mathrm{PCO}_{2}$ during spontaneous ventilation, at a time when the VD/VT was increased to almost double the normal range. It is probable that hypoxaemia, even of a mild nature, contributes to the excessive ventilatory drive.

Pulmonary fat embolism differs from the other forms of embolism in a number of ways, in particular in its gradual onset and progressive elution through the pulmonary circulation into the systemic capillary bed. The gradual onset of symptoms may be accounted for by the diffuse spatial distribution of emboli in lung capillaries (Szabó, Jankovics, Magyar, Szabó, and Szepeshazy, 1967) and to some extent by the time scale of embolism and disappearance of fat from the pulmonary capillaries (Szabó et al, 1967). The latter factor is emphasized by the progressive improvement in VD/VT with time in our patients.

Arterial hypoxaemia is now widely recognized as a major feature of the clinical syndrome of fat. embolism. In severe cases, the marked desatura- 
tion of arterial blood is clinically obvious from the cyanosis, and yet arterial saturation levels provide only coarse indications of the severity of disturbance of pulmonary gas exchange. In patients breathing air, a fall in $\mathrm{PaO}_{2}$ from 90 to $60 \mathrm{~mm} \mathrm{Hg}$ represents a significant deterioration of gas exchange, but is equivalent to a reduction of arterial $\mathrm{O}_{2}$ saturation of only $7 \%$, a change which may not be clinically recognized except under ideal lighting conditions. Changes in the alveolar-arterial $\mathbf{P O}_{2}$ difference estimated at two different levels (breathing air or $100 \%$ oxygen) give a much more sensitive index of the proportion of the cardiac output which is effectively perfusing alveoli which are either seriously underventilated or frankly collapsed (Nunn, 1966). In this study, the levels of pulmonary venous admixture found which were equivalent to collapse of between 30 and $50 \%$ of the lung cannot necessarily be attributed to the effects of vascular occlusion (Kovacs, Hill, Abert, Blesovsky, and Gerbode, 1966). Clearly a different mechanism must be implicated in order to explain the difference in the time course of the changes in $V_{D} / V_{T}$ and those of pulmonary venous admixture. The hypothesis advanced by Szabó, Magyar, and Jankovics (1968) attributes the arterial desaturation following pulmonary fat embolism to inflammatory reaction and exudation into the alveoli as a result of free fatty acids released from the embolized neutral fat. This hypothesis is doubly attractive in that Szabó and his colleagues demonstrated that these inflammatory reactions occurred immediately after infusion of free fatty acids but only gradually after infusion of neutral fats, thus confirming the earlier studies of Peltier (1956) and de Ruiter (1966) on the pulmonary toxicity of oleic acid. De Ruiter's findings of bloodstained, frothy nasal discharge and postmortem evidence of haemorrhagic alveolar exudates and heavy, oedematous lungs are characteristic of the clinical syndrome, and are fully compatible with both the clinical findings and the disturbances of gas exchange found in our patients.

Patients with preexisting or coexisting pulmonary pathology might be expected to be predisposed towards a more severe manifestation of fat embolism in terms of arterial hypoxaemia and its secondary effects. Szabó et al (1969) have shown that a preexisting pneumothorax increases the mortality of experimental fat embolism, decreases the lethal dose of neutral fat, and causes severe desaturation of arterial blood. Such a combination could occur after combined chest and long bone injuries sustained in road traffic accidents. The converse effect, the occurrence of a pneumothorax during the recovery from fat embolism, was seen in case 1 on the eleventh day after admission and caused a sudden worsening of his pulmonary venous admixture. Drainage of his pneumothorax caused a partial resolution only of the changes in arterial $\mathrm{PO}_{2}$. Concurrent infection of the lung is more likely to occur in patients with preexisting fat embolism, since the pulmonary exudate is an ideal culture medium for pathogenicobacteria. Both the patients in our series who died showed multiple areas of suppurative pneumonias? and abscess formation.

The role of hypoxaemia in the causation of the central nervous disturbances associated with cere $-\frac{\bar{c}}{\frac{5}{b}}$. bral fat embolism cannot be ascertained from the results of our studies, but the full and rapidw neurological recovery made by patients in this and other series does not compare with the end results in patients who have suffered a period of $\bar{\epsilon}$ severe hypoxia. Conversely, it is difficult to pros vide an explanation of the disturbances in pulo monary gas exchange on a neurological basis. It therefore seems probable that the clinical syn $\rightarrow$ drome can be attributed to the combination of the neurological effects of cerebral fat embolism and the biphasic disturbances of gas exchange arising from the initial embolization of fat in the puls monary capillaries. To what extent either pre $\overrightarrow{\bar{c}}$ dominates is dependent on a number of othes factors, most of which weigh heavily in favour of augmenting the pulmonary disturbances.

\section{Summary}

Investigations of pulmonary gas exchange have been carried out in five patients in whom a clinica? diagnosis of fat embolism was established. Raise $\$$ dead space/tidal volume ratios $(48-60 \%)$ during the early stages of the condition indicated the degree of pulmonary vascular occlusion and re duced perfusion of alveoli, and the improvement of this index with time was compatible with the progressive disappearance of fat from the pulmorio ary circulation. Increased pulmonary venous ad mixture $(20-55 \%)$ was responsible for the markeg desaturation of arterial blood in patients breathe ing air, and was present shortly after embolisn? but did not decrease to normal levels in parallet with the improvement in pulmonary perfusio This biphasic response may be interpreted as evidence of residual alveolar damage arising from the initial embolization of fat in the pulmonas capillaries.

Professor Nunn and Dr G. R. Kelman were § receipt of a grant from the Medical Research Council, and Dr R. Greenbaum was in receipt $\overline{\text { If }}$ a Leverhulme research fellowship. The authogs would like to thank Mr F. F. Silk for the of portunity to study patients under his care, and Dr M. D. Hargreaves for the measurements airway mechanics. 
References

Armin, J., and Grant, R. T. (1951). Observations on gross pulmonary fat embolism in man and in the rabbit. Clin. Sci., $10,441-469$.

Binger, C. A., Brown, G. R., and Branch, A. (1924). Experimental studies on rapid breathing. I: Tachypnea independent of anoxemia, resulting from multiple emboli in the pulmonary arterioles and capillaries. J. clin. Invest., 1, 127-180.

Collins, J. A., Gordon, W. C., Jr., Hudson, T. L., Irvin, R. W., Kelly, T., and Hardaway, R. M., III (1968). Inapparent hypoxaemia in casualties with wounded limbs: Pulmonary fat embolism? Ann. Surg., 167, 511-520.

Eckenhoff, J. E., Enderby, G. E. H., Larson, A., Edridge, A., and Judevine, D. E. (1963). Pulmonary gas exchange during deliberate hypotension. Brit. J. Anaesth., 35, 750-759.

Enghoff, H. (1938). Volumen inefficax. Bemerkungen zur Frage des schädlichen Raumes. Upsala-Läk.-Fören. Förh., 44, 191-218.

Freeman, J., and Nunn, J. F. (1963). Ventilation-perfusion relationships after haemorrhage. Clin. Sci., 24, 135-147.

Gerst, P. H., Rattenborg, C., and Holaday, D. A. (1959). The effects of hemorrhage on pulmonary circulation and respiratory gas exchange. J. clin. Invest., 38, 524-538.

Greenbaum, R., Nunn, J. F., Prys-Roberts, C., Kelman, G. R., and Silk, F. F. (1965). Cardiopulmonary function after fat embolism. Brit. J. Anaesth., 37, 554-555.

Gröndahl, N. B. (1911). Untersuchungen über Fettembolie. Dtsch. Z. Chir., 111, 56-124.

Kelman, G. R., Coleman, A. J., and Nunn, J. F. (1966). Evaluation of a microtonometer used with a capillary glass electrode. J. appl. Physiol., 21, 1103-1107.

Kelman, G. R., and Prys-Roberts, C. (1967). Circulatory influences of artificial ventilation during nitrous oxide anaesthesia in man. I. Introduction and methods. Brit. $J$. Anaesth., 39, 523-532.

Kovacs, G. S., Hill, D., Abert, T., Blesovsky, A., and Gerbode, F. (1966). Pathogenesis of arterial hypoxemia in pulmonary embolism. Arch. Surg., 93, 813-823.

Linden, R. J., Ledsome, J. R., and Norman, J. (1965). Simple methods for the determination of the concentrations of carbon dioxide and oxygen in blood. Brit. J. Anaesth., $37,77-88$.

Nunn, J. F. (1963). Indirect determination of the ideal alveolar oxygen tension during and after nitrous oxide anaesthesia. Brit. J. Anaesth., 35, 8-10.

Nunn, J. F. (1966). The lung as a black box. Canad. Anaesth. Soc. J., 13, 81-97.

Nunn, J. F. (1969). Applied Respiratory Physiology, with Special Reference to Anaesthesia. Butterworths, London.

Peltier, L. F. (1956). Fat embolism. III. The toxic properties of neutral fat and free fatty acids. Surgery, 40, 665-670.

Peltier, L. F. (1967). Fat embolism: a pulmonary disease. Surgery, 62, 756-758.

Riley, R. L., Cournand, A., and Donald, K. W. (1951). Analysis of factors affecting partial pressures of $\mathrm{O}_{2}$ and $\mathrm{CO}_{2}$ in gas and blood of lungs: methods. J. appl. Physiol., 4, 102-120.

Ruiter, H. de (1966). Traumatic fat embolism. Thesis, University of Amsterdam.

Severinghaus, J. W., and Stupfel, M. (1957). Alveolar dead space as an index of distribution of blood flow in pulmonary capillaries. J. appl. Physiol., 10, 335-348.

Sevitt, S. (1962). Fat Embolism. Butterworths, London.

Sproule, B. J., Brady, J. L., and Gilbert, J. A. L. (1964). Studies on the syndrome of fat embolization. Canad. med. Ass. J., 90, 1243-1247.

Stein, M., Forkner, C. E., Jr., Robin, E. D., and Wessler, S. (1961). Gas exchange after autologous pulmonary embolism in dogs. J. appl. Physiol., 16, 488-492.

Szabó, G., Jankovics, R., and Farkas, G. (1969). Pathomechanism of fat embolism. IV. Cerebral and pulmonary factors in the fat embolism syndrome. Acta med. Acad. Sci. hung., 26, 143-155.

Szabó, G., Jankovics, R., Magyar, Z., Szabó, A., and Szepeshazy, K. (1967). The pathomechanism of fat embolism. I. Comparative quantitative study of human and experimental fat embolism. Acta med. Acad. Sci. hung., 24, 299-313.

Szabó, G., Magyar, Z., and Jankovics, R. (1968). Fatty acid poisoning as a possible factor producing the syndrome of fat embolism. Acta med. Acad. Sci. hung., 25, 331-343.

Wertzberger, J. J., and Peltier, L. F. (1968). Fat embolism: the importance of arterial hypoxia. Surgery, 63, 626-629.

\section{Discussion: Fat embolism}

\section{I. GRAHAM}

From the Institute of Neurological Sciences, Glasgow

Dr A. J. Watson has commented on the presence of petechial haemorrhages in the white matter of the brain in systemic fat embolism. His description seems to be accepted by most pathologists as typical of the naked-eye appearances in such cases. An example recently encountered in the Institute appears therefore to be of particular interest. This was a 33-year old woman who died of fulminating systemic fat embolism 29 hours after a road traffic accident in which one femur was fractured. At necropsy the brain was pale and rather swollen but, on section, there were no apparent focal naked-eye abnormalities in either the gray or white matter. The examination of large celloidin sections, however, disclosed innumerable foci of neuronal necrosis which, although predominant in the cerebral and cerebellar cortex, were also present in the basal ganglia and white matter (Fig.). I would

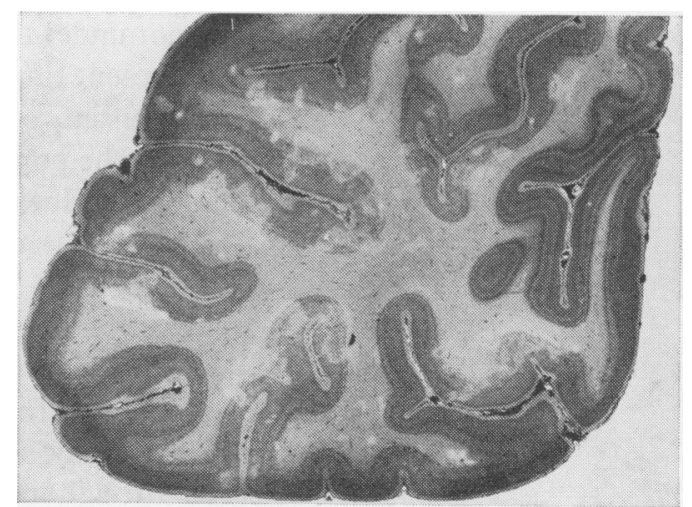

Fig. Occipital lobe: there are numerous randomly distributed foci of ischaemia in the cortex and at the corticomedullary junction. Similar but fewer lesions are seen in the white matter. Cresyl violet $\times 3$.

like to know how unusual the distribution of the: pathological changes in this case is and whether lesions in the gray matter, if they have not been associated with petechiae, have been insufficiently recognized in the past. 